\title{
Human-based social interaction can reward a rat's behavior
}

\author{
HANK DAVIS and RACHELLE PÉRUSSE \\ University of Guelph, Guelph, Ontario, Canada
}

\begin{abstract}
Rats were trained to leverpress in a conventional operant test chamber; however, their behavior was rewarded solely by social interaction with a human being. This training was successful for half the subjects tested; success was confined to animals for which social interaction had occurred prior to training. Similar findings with other species are discussed. Although the effects of social interaction with a human are by no means as robust as those of food to a hungry animal, the present results suggest that the human-rat interaction may be a positive adjunct to conventional behavioral training techniques, and a possible confound where its effects are uncontrolled.
\end{abstract}

The rat has been a versatile experimental subject for over three quarters of a century (Munn, 1950). In this role, rats are frequently tickled, scratched, petted, carried to and fro, and handled extensively during the course of an experiment. However, such handling may have profound and sometimes unanticipated effects on rat subjects. For instance, interaction with a human in a laboratory setting has been linked with weight gain (McClelland, 1956; Weininger, McClelland, \& Arima, 1954), increased activity (Ruegamer, Bernstein, \& Benjamin, 1954; Weininger, 1956), resistance to stress (Ader, 1959), decreased emotionality (Spence \& Maher, 1962), decreased timidity (Hunt \& Otis, 1955), and superior learning (Bernstein, 1957).

In addition to human-rat interactions in the laboratory, there are numerous, if less systematically reported, cases of rats making affectionate and responsive pets. ${ }^{1}$ Surprisingly, however, there is considerable experimental evidence to suggest that rats find contact with a human to be aversive. Research in this area has typically employed a technique known as "gentling," during which the experimenter holds the rat in one hand while stroking the animal with the other hand at a constant rate of $\mathbf{5 0}$ strokes per minute (Weininger, 1956). Such research has shown that rats will not only avoid this kind of "gentling" when given a choice, but will also learn behaviors to avoid being "gentled" (Candland, Faulds, Thomas, \& Candland, 1960). On the basis of this evidence, it was concluded that gentling had negative "reinforcing properties similar to stimulation such as electric shock" (Candland, Horowitz, \& Culbertson, 1962, p. 1064).

The results of "gentling" research, however, are far from conclusive. Specifically, it is not clear whether rats

\footnotetext{
This research was supported in part by Grant A06973 from the Natural Science and Engineering Research Council of Canada. A portion of this report was presented at the June 1985 meeting of the Animal Behavior Society. The authors thank J. L. Mottin for his critical assistance. Rachelle Pérusse is now at Georgia State University, Atlanta, GA. H. Davis's mailing address is Department of Psychology, University of Guelph, Guelph, ON N1G 2W1, Canada.
}

were responding negatively toward human-based interaction per se, or to the particular method of handling employed. In short, it may be that handling as defined by 50 strokes/min, and not interaction with a human being, is aversive. It would thus not be surprising to find that rats find other types of human contact to be a positive experience. In one such study (Werner \& Latané, 1974), an experimenter's hand movements attempted to simulate rats at play by "poking, lifting, rubbing and scratching, tapping and tumbling." These researchers concluded that contact with the human hand was as attractive as contact with another rat, thereby suggesting that a human-rat interaction can be a preferred activity (Werner $\&$ Anderson, 1976; Werner \& Latané, 1974).

In the present paper, we report that human-based social interaction can, indeed, be a positive experience for rats, and that this interaction, in and of itself, can be sufficiently rewarding to modify the rat's behavior. Our attempt to use human contact as a behavioral incentive is not without precedent. Tactile stimulation (petting) has been utilized as an effective reward for instrumental behavior in both dogs (Kostarczyk \& Fonberg, 1982) and cats (Wenzel, 1959). In our study, rat subjects were taught to make contact with a small metal lever via the process of shaping, whereby successive approximations to the target behavior were rewarded. Reward consisted solely of petting and spontaneous social interaction. Other potential reinforcers, such as food or water, were never introduced into the experimental situation.

\section{METHOD}

\section{Subjects}

A total of 17 male and female rats of the Wistar strain, approximately 120 days old at the start of testing, were used as subjects. The rats were housed individually with food and water available in their home cages ad lib.

\footnotetext{
Apparatus

The apparatus was a specially modified Lehigh Valley Electronics operant test chamber that allowed the experimenter access to the
} 
animal via a $13.5 \times 23 \mathrm{~cm}$ opening on the wall adjacent to the lever in the side panel of the cage.

\section{Procedure}

The animals were assigned randomly to either a preexposed or a nonexposed condition. The preexposed group $(N=8,3$ male, 5 female) was allowed to interact freely with the experimenter during 25 daily $1 / 2$-h sessions prior to the start of shaping. The humanbased social interaction during this period included, but was not restricted to, the type of tactile stimulation subjects were to subsequently receive as reward. The experimenter picked up, petted, spoke to, and allowed the rat to continuously climb on her person. The nonexposed group ( $N=9,5$ male, 4 female) spent this period in their home cages and were shaped without prior exposure to the experimenter. Once shaping commenced, all extraneous experiment-subject interaction ceased.

Prior to shaping, each subject was placed into the test chamber for $20 \mathrm{~min}$ to determine its baseline rate of lever contact. The nonexposed animals made an average of 1.6 responses during this session; preexposed animals averaged 0.8 responses during the same period. No subject responded more than twice. Following this baseline session, the subjects were individually placed into the test chamber for daily 25 -min acquisition sessions. Shaping was performed in a manner identical to its use with conventional food reward; that is, subjects were initially rewarded for movement and orientation toward the lever. Such shaping was maintained until 15 or more lever contacts occurred during a single session. At that point, testing was begun and the number of lever contacts was recorded for each session.

A "lever touch" occurred whenever an animal made contact with the lever, using either of its two front paws. A leverpress occurred when the animal pressed the lever with its paw, using sufficient pressure to close the microswitch and produce an audible click. Each time a target behavior was emitted, the experimenter praised the subject verbally ("'good girl," “"way to go!") while simultaneously reaching into the test chamber to physically interact with (i.e., pet, tickle) the rat for approximately $5 \mathrm{sec}$.

Once an animal made a total of 15 or more responses per session for seven sessions, testing was complete and extinction trials were begun. Extinction consisted of placing the rat in the chamber for $25 \mathrm{~min}$ per session and recording the number of lever contacts in the absence of human interaction. Extinction was complete when the subject made five or fewer responses during each of four consecutive sessions.

All test situations were videotaped and scored by a second observer who was unaware of whether subjects belonged to the preex posed or nonexposed condition.

\section{RESULTS}

Four ( 2 male and 2 female) of the 8 rats from the preexposed condition successfully learned to contact the lever in order to be rewarded by human-based social interaction. No animal from the nonexposed group acquired a lever response. Training of the remaining 4 preexposed rats and all 9 nonexposed rats was discontinued at different points during the shaping sequence if (1) the animal began to display with increasing frequency behaviors incompatible with shaping (e.g., freezing, trembling, escaping), or (2) the animal failed to make enough responses to warrant more than 10 interactions per session for three consecutive sessions. By the fifth session, criterion 2 was responsible for the discontinuation of training for 4 of the 8 preexposed rats, and 7 of the 9 nonexposed rats. ${ }^{2}$

Within the preexposed group, 4 rats learned to contact the lever to criterion for human-based reward. Although all lever contacts were rewarded, three different response topographies emerged. These data are summarized in Table 1 , which reports the number of responses per test session and the number of shaping sessions taken to reach criterion. The occurrence of leverpressing for social reward was not regularly distributed, but rather occurred in irregularly spaced bursts of 3-5 responses within the session.

All successful rats displayed higher performance rates during social interaction sessions than during the pretest baseline and subsequent extinction sessions $(p<.01$, randomization test; interobserver reliability $=1$ ). All subjects continued to leverpress in the absence of social reinforcement for between one and three sessions before reducing their rates to meet the extinction criterion. These data, also, are summarized in Table 1.

\section{DISCUSSION}

We have demonstrated that human-based social interaction can be an effective reward for instrumental behavior in both male and female rats that have had prior contact with that human. We believe that the increased frequency

Table 1

Number of Lever Contacts Made by Four Successful Rat Subjects for Human-Based Social Interaction

\begin{tabular}{|c|c|c|c|c|c|c|c|c|c|c|c|}
\hline \multirow[b]{2}{*}{ Rat Name } & \multirow[b]{2}{*}{ Response } & \multirow{2}{*}{$\begin{array}{c}\text { Number of } \\
\text { Shaping } \\
\text { Sessions }\end{array}$} & \multirow{2}{*}{$\begin{array}{c}\text { Baseline } \\
\text { Rate } \\
\end{array}$} & \multirow{2}{*}{$\begin{array}{c}\text { Response } \\
\text { Rate }\end{array}$} & \multicolumn{7}{|c|}{ Test Session Number } \\
\hline & & & & & 1 & 2 & 3 & 4 & 5 & 6 & 7 \\
\hline \multirow{2}{*}{$\begin{array}{l}\text { Dos Equis } \\
\text { (male) }\end{array}$} & Leverpress & 8 & 1 & Testing & 16 & 26 & 22 & 15 & 20 & 17 & 16 \\
\hline & & & & & & & & & & & $x$ \\
\hline \multirow{2}{*}{$\begin{array}{l}\text { Townsley } \\
\text { (female) }\end{array}$} & Leverpress & 6 & 0 & Testing & 19 & 19 & 17 & 22 & 16 & 16 & 15 \\
\hline & & & & Extinction & 12 & 6 & & 5 & 2 & 5 & 4 \\
\hline \multirow{2}{*}{$\begin{array}{l}\text { Squeakies } \\
\text { (female) }\end{array}$} & Lever Touch & 9 & 0 & Testing & 31 & 18 & 18 & 16 & 20 & 18 & 35 \\
\hline & & & & Extinction & 13 & & & & & & 2 \\
\hline \multirow{2}{*}{$\begin{array}{l}\text { Kringlechip } \\
\text { (male) }\end{array}$} & Lever Gnaw & 5 & 0 & Testing & 49 & 33 & 24 & 24 & 22 & 25 & 28 \\
\hline & & & & Extinction & 9 & 2 & 0 & 4 & 4 & $\mathbf{x}$ & $\mathbf{x}$ \\
\hline
\end{tabular}

Note-Data were recorded during a prereward baseline session and testing and extinction sessions. 
of lever contact reflects a learned response maintained by social reinforcement, and is not simply a byproduct of increased activity or exploratory behavior directed toward the experimenter's hand. ${ }^{3}$

Our results and similar ones reported by Werner and Anderson (1976) are in direct conflict with much of the "gentling" literature mentioned above. Collectively, they suggest that although some forms of human-rat interaction may be aversive to the rat, there are at least some interactions between human and rat that are positive enough to modify the rat's behavior in the absence of conventional food reward.

The present data are consistent with previous reports showing that the rewarding effects of human-based social interaction on rats, cats, and dogs are either augmented by or totally dependent upon prior social exposure to a human (Anderson \& Gantt, 1966; Wenzel, 1959; Werner \& Latané, 1974). Although preexposure to a human may result in greater tractability with humans in general, the more profound social effects, such as those involved in reinforcement, may be confined to the particular human to whom the rat was preexposed. Indeed, pilot data using the present procedure, as well as previous findings reported by Werner and Latané (1974), suggest that this is precisely the case.

It is important to address the question of why only half the rats in the preexposure group learned an instrumental response to receive human-based social interaction. This dichotomy between rats in the present study probably reflects a similar dichotomy in the general laboratory rat population, despite the fact that these animals have been selectively bred for docility and tameness (Barnett, 1963).

The fact that not all subjects respond positively to humans is not unique to rats. Even dogs, a species renowned for its responsiveness to human contact, do not uniformly acquire an instrumental response to receive petting as reinforcement (Kostarczyk \& Fonberg, 1982).

What might account for such differences in an animal's response to human-based interaction? It is notable that petting has been shown to produce cardiac deceleration (bradycardia) in some, but not all, dogs (Anderson \& Gantt, 1966; Gantt, Newton, Royer, \& Stephens, 1966; Lynch \& McCarthy, 1967). Moreover, bradycardia was observed only in those animals that were susceptible to the rewarding effects of tactile stimulation, and not in animals that were not (Kostarczyk \& Fonberg, 1982, p. 30). These findings have led to the conclusion that " tactile stimulation evokes cardiac deceleration [only] when its emotional content is pleasant and rewarding" (Kostarczyk \& Fonberg, 1982, p. 30). Comparable cardiac deceleration in response to rewarding brain stimulation has been found in rats (Ross \& Malmo, 1979). We hope eventually to demonstrate bradycardia in those rats for which human-based social interaction is rewarding enough to support instrumental conditioning. Such a physiological correlate might then be used as a predictor for how an animal will respond to human interaction.
Unlike conventional food reward with hungry rats, the use of human-based social interaction does not appear potent enough to maintain a high rate of leverpressing throughout a session, although response totals might have been higher had reward been delivered on an intermittent schedule. It is also notable that the rate of behavior maintained by this reinforcer did not systematically increase across sessions. We are therefore not suggesting that, instead of conventional food or water reinforcement, human-based social reward be used with rats. Rather, we have attempted to demonstrate that its effects are sufficiently potent to shape and maintain operant behavior of rats, and should therefore not be overlooked in the experimental analysis of this species' behavior.

Putting the case simply, the handling of rat subjects by human experimenters is inevitable; the interactions that result from this handling may have profound effects. Acknowledging them may allow us to use human contact as an adjunct to conventional conditioning techniques (e.g., Davis, 1986; Davis \& Bradford, 1986). Indeed, prior human-rat contact may facilitate the subsequent learning of a leverpress response in operant test situations (e.g., West \& Michael, 1987). Failure to acknowledge the effects of human-based social interaction, especially when such contact occurs on a trial-by-trial basis, may result in poorly designed experimental situations or confounded data. Such concerns have been amply expressed when other species are involved (e.g., Sebeok \& Rosenthal, 1981); we be- lieve it is time to extend this awareness to behavioral work with the rat.

\section{REFERENCES}

ADER, R. (1959). The effects of early experience on subsequent emotionality and resistance to stress. Psychology Monographs, 73(Whole No. 472).

ANDERSON, S., \& GANTT, W. H. (1966). The effect of person on cardiac and motor responsivity to shock in dogs. Conditional Reflex, 1, 181-189.

BaRnetT, S. A. (1963). A study in behavior. Chicago: Aldine.

BERNSTEIN, L. (1957). Effects of variations in handling upon learning and retention. Journal of Comparative \& Physiological Psychology, 50, 162-167.

Candland, D., Faulds, B., Thomas, D., \& Candland, M. (1960). The reinforcing value of gentling. Joumal of Comparative \& Physiological Psychology, 53, 55-58.

Candland, D., Horowitz, S., \& Culbertson, J. (1962). Acquisition and retention of acquired avoidance with gentling as reinforcement. Journal of Comparative \& Physiological Psychology, 55, $1062-1064$.

DAvis, H. (1986, November). Self-imposed feeding restraint in the rat: A numerical discrimination. Paper presented at the meeting of the Psychonomic Society, New Orleans, LA.

Davis, H., \& BradFord, S. A. (1986). Counting behavior by rats in a simulated natural environment. Ethology, 73, 265-280.

Gantt, W. H., Newton, J. E., Royer, F. L., \& Stephens, J. H. (1966). Effect of person. Conditional Reflex, 1, 18-34.

HuNT, H., \& OTIS, L. S. (1955). Restricted experience and "timidity" in the rat. American Psychologist, 10, 432.

Kostarczyk, E., \& FonberG, E. (1982). Heart rate mechanisms in instrumental conditioning reinforced by petting in dogs. Physiology \& Behavior, 28, 27-30. 
LYNCH, J. J., \& MCCARTHY, J. F. (1967). The effect of petting on a classically conditioned emotional response. Behavior Research \& Therapy, 5, 55-62.

MCCleLLAND, W. (1956). Differential handling and weight gain in the albino rat. Canadian Journal of Psychology, 10, 19-22.

MuNn, N. L. (1950). Handbook of psychological research on the rat. New York: Houghton Mifflin.

Ross, A. R., \& MaLmo, R. B. (1979). Cardiovascular responses to rewarding brain stimulation. Physiology \& Behavior, 22, 1005-1013.

Ruegamer, W., Bernstein, L., \& Benjamin, J. (1954). Growth, food utilization, and thyroid activity in the albino rat. Science, 120, 184-185.

Sebeok, T. A., \& Rosenthal, R. (1981). The Clever Hans phenomenon: Communication with horses, whales, apes, and people. Annals of New York Academy of Sciences, 364, 309 p.

SPEnCE, J. T., \& MaHER, B. A. (1962). Handling and noxious stimulation of the albino rat: I. Effects on subsequent emotionality. Journal of Comparative \& Physiological Psychology, 55, 247-251.

WEININGER, O. (1956). The effects of early experience on behavior and growth characteristics. Joumal of Comparative \& Physiological Psychology, 49, 1-9.

Weininger, O., McClelland, W., \& Arima, R. (1954). Gentling and weight gain in the albino rat. Canadian Jourmal of Psychology, 8, 147-151.

WENZEL, B. (1959). Tactile stimulation as reinforcement for cats and its relation to early feeding experience. Psychological Reports, 5 , 297-300.

WERNER, C., \& ANDERSON, D. F. (1976). Opportunity for interaction as reinforcement in a T-maze. Personality \& Social Psychology Bulletin, 2, 166-169.

WeRner, C., \& LATANÉ, B. (1974). Interaction motivates attraction: Rats are fond of fondling. Journal of Personality \& Social Psychology, 29, 328-334.
West, C. H. K., \& MichaEL, R. P. (1987). Handling facilitates the acquisition of lever-pressing for brain self-stimulation in the posterior hypothalamus of rats. Physiology \& Behavior, 39, 77-81.

\section{NOTES}

1. "Pet rat saves Toledo woman from fire in bed," Toledo Ohio Blade, March 18, 1984.

2. Extended training is unlikely to reverse the effects of social interaction. It is notable that during pilot work, 1 subject failed to respond positively to human contact even after as many as $\mathbf{5 0}$ sessions.

3. We recognize that rats will approach a hand that interacts with them (Werner \& Latané, 1974). However, we believe that such an account of the present results is inadequate for several reasons. (1) Animals repeatedly initiated bursts of leverpressing following periods of inactivity when no hand was present for several minutes or more. In short, the hand often followed, rather than preceded, a lever contact. (2) The location of the wall opening through which the hand appeared was not in immediate physical proximity to the lever, and was thus unlikely to generate spurious arousal-based lever contact. Moreover, during pilot work, the position of the experimenter's hand was even further removed from the lever (entry into the cage was made through the open lid). Although the appearance of the hand from this location was even less likely to engender spurious lever contact through approach or investigation, a similar rate of leverpressing for social reward was recorded under these conditions.

(Manuscript received January 29, 1987; revision accepted for publication July 28,1987 .) 